\title{
Perintisan Perpustakaan di Madin Salawiyah Desa Ngombak Kecamatan Kedungjati, Grobogan \\ Rasiman $^{1}$, Umar Hafidz Asy'ari Hasbullah ${ }^{1}$, Dwi Prasetyo Hadi ${ }^{1}$, Adhy Purnomo ${ }^{2}$ \\ ${ }^{1}$ UPGRIS Semarang; ${ }^{2}$ Politeknik Negeri Semarang \\ mpdrasiman@yahoo.co.id
}

Key word:

Pioneer;

library;

Islamic School

Kata Kunci

Perintisan;

Perpustakaan;

Madin

\section{Abstract}

Madrasah Diniyah (Madin) as one of the non-formal educational institutions that is needed by the community at this time to provide provisions as the successor to the nation. So that the learning process in Madin runs well, various facilities are needed, including the availability of a library. The library is a place to find information sharing knowledge for students (santri). The availability of libraries in Madin Salawiyah, Ngombak Village, Kedungjati Sub-district, can help students form the habit of reading and seeking knowledge for students. Observation results show that: (1) open services are services that give students the opportunity to choose free books to read and take home, (2) closed services namely services that allow participants to visit the library at certain hours, and (3) students Madin Salawiyah showed high enthusiasm to visit the library. The results of dedication to library services can improve the optimization of services to students, scholars, clerics by applying the simplicity of service, responsibility, and convenience. In addition, good library services can have a good impact on library users, such as being able to motivate friends to actively read books, increase knowledge, make it easier to complete the tasks of the clerics and religious teachers. Therefore, the library Madin Salawiyah continues to evaluate the performance and quality of the library in order to create a conducive atmosphere for students in reading.

\section{Abstrak}

Madrasah Diniyah (Madin) sebagai salah satu institusi pendidikan non formal yang sangat dibutuhkan masyarakat pada saat ini untuk memberi bekal sebagai penerus bangsa. Agar proses pembelajaran di Madin berjalan dengan baik, maka diperlukan berbagai fasilitas, antara lain tersedianya perpustakaan. Perpustakaan adalah satu tempat untuk mencari informasi berbagi ilmu pengetahuan bagi santri (santri). Tersedianya perpustakaan di Madin Salawiyah Desa Ngombak Kecamatan Kedungjati dapat membantu santri dalam membentuk kebiasaan membaca dan mencari ilmu bagi para santri. Hasil observasi menunjukkan bahwa: (1) pelayanan terbuka yaitu pelayanan yang memberi kesempatan santri bebas untuk memilih buku yang akan dibaca dan di bawa pulang, (2) pelayanan tertutup yaitu pelayanan yang memperbolehkan peserta mengunjungi perpustakaan pada jam tertentu, dan (3) santri Madin Salawiyah menunjukkan antusias yang tinggi untuk mengunjungi perpustakaan. Hasil pengabdian menunuukkan pelayanan perpustakaan dapat meningkatkan optimalisasi layanan kepada santri, kiai, ustad dengan 
cara menerapkan kesederhanaan layanan, tanggung jawab, dan kemudahan. Selain itu juga dengan pelayanan perpustakaan yang baik, dapat menimbulkan dampak yang baik terhadap pengguna perpustakaan, seperti dapat memotivasi teman supaya giat membaca buku, meningkatkan pengetahuan, memudahkan menyelesaikan tugas dari kiyai dan ustad. Oleh sebab itu, pihak perpustakaan Madin Salawiyah terus mengevaluasi kinerja dan kualitas perpustakaan demi mencipkatan suasana yang kondusif bagi santri dalam membaca.

\section{PENDAHULUAN}

Perpustakaan merupakan salah satu sumber belajar yang penting, yang memungkinkan tenaga pendidik dan santri memperoleh kesempatan untuk memperluas dan memperdalam pengetahuan dengan membaca bahan pustaka yang mengandung ilmu pengetahuan yang diperlukan. Perpustakaan merupakan unit kerja yang menghimpun, mengelola dan menyajikan kekayaan intelektual untuk kepentingan pendidikan, penelitian, pelestarian, informasi dan rekreasi untuk mencerdaskan kehidupan bangsa. Perpustakaan berguna untuk meningkatkan mutu pendidikan, dengan tujuan menggalakkan keaksaraan, mendukung kurikulum pendidikan secara umum dan mengembangkan minat membaca. Perpustakaan juga memiliki peran penting dalam menumbuhkan budaya literasi di kalangan santri madrasah (Rasyid, 2017).

Adapun saat ini, banyak perpustakaan yang berada di sekolah maupun di lembaga mengalami kendala seperti keberadaan perpustakaan belum mendapat perhatian serius dalam dunia pendidikan serta kurangnya pelayanan terhadap perpustakaan di beberapa sekolah maupun perguruan tinggi, perpustakaan diposisikan sebagai pelengkap saja. Dalam Undang-Undang RI Nomor 20 Tahun 2003 tentang Sistem Pendidikan Nasional disebutkan bahwa sumber daya pendidikan adalah segala sesuatu yang digunakan dalam penyelenggaraan pendidikan, meliputi tenaga kependidikan, masyarakat, dana, sarana dan prasarana.

Salah satu faktor perpustakaan di Madin akan dikunjungi dan diminati santri, kiai maupun ustad adalah layanan perpustakaan yang tergolong baik berdasarkan indikator penilaian merujuk pada lembaga administrasi Negara prinsip-prinsip layanan meliputi: (1) kesederhanaan dan tanggung jawab dari petugas layanan perpustakaan,

kecakapan para petugas layanan perpustakaan, (3) kedekatan kepada pengunjung, (4) dan kemudahan kontak antara petugas dan pelanggan, keramahan, keterbukaan, komunikasi antar petugas dan pengguna, kredibilitas, kejelasan dan kepastian, 
keamanan, mengerti harapan pelanggan, kenyataan, efisien, dan ekonomis.

Madrasah Diniyah Salawiyah belum mempunyai perpustakaan secara permanen, pada saat ini perpustakaan yang dimiliki masih menjadi satu dengan ruang ustad dan juga penerapannya dibawah standar pelayanan yang baik berdasarkan standar pelayanan administrasi Negara. Pihak Madrasah Diniyah perlu mendapatan bimbingan dan arahan dalam merintis perpustakaan yang terpisah dengan ruang ustad dan menata pelayanan perpustakaan agar lebih baik. Penataan pelayanan perpustakaan meliputi perencanaan, pengorganisasian, pengarahan, dan pengawasan.

Penerapan layanan merupakan salah satu tugas utama suatu perpustakaan agar sumber- sumber informasi yang dimiliki dapat dimamfaatkan oleh pemakai secara maksimal. Namun kenyataan pada saat ini perintisan perpustakaan di Madin Salawiyah masih memiliki kekurangan seperti kurangnya pengelolaan atau manajemen perpustakaan, baik dari tempat, penataan buku, sampai dengan kurangnya buku. Menurut Sutarno (2008: 132), banyak sekali perpustakaan baik di lembaga pendidikan maupun di komunitas masyarakat yang belum berfungsi maksimal. Dari beberapa perpustakaan yang dibangun ada yang kemudian redup penyelenggaraannya dan bahkan ada yang mati.

\section{METODE PEMECAHAN MASALAH}

Metode yang digunakan dalam kegiatan ini adalah observasi, wawancara, dan dokumentasi. Hasil pengumpulan data ini, digunakan sebagai dasar untuk melakukan kegiatan perintisan perpustakaan sehingga diperoleh perpustakaan yang mempunyai ruang sendiri, almari, dan berbagai buku serta tempat membaca yang nyaman.

Metode observasi yang digunakan adalah non partisipasi, berarti observer tidak terlibat secara langsung dalam kegiatan pengamatan dilapangan. Di samping itu juga dilakukan observasi partisipasi, maksudnya ialah observer melihat dan mengamati apa yang terjadi di lapangan secara langsung. Jika data masih kurang lengkap atau belum memadai, maka dilengkapi dengan metode Interview dan dokumentasi.

Peningkatan layanan Perpustakaan Madin Salawiyah Desa Ngombak, maka perlu dilakukan redesain sesuai standar pengelolaan perpustakaan profesional. Redesain perpustakaan dilakukan melalui metode dan pendekatan partisipatif, artinya, masyarakat pesantren (pengelola perpustakaan, santri, ustadz, pengasuh 
pesantren) akan dilibatkan secara penuh dalam proses penataan kembali perpustakaan agar mendekati kondisi yang ideal bagi sebuah lembaga pendidikan. Dalam pendekatan partisipatif ini, pada tahap awal akan dilakukan Participatory Rural Appraisal (PRA), yaitu metode untuk mendapatkan deskripsi persoalan perpustakaan dengan melibatkan masyarakat pesantren secara penuh. Pelaksanaan PRA sangat bermanfaat agar masyarakat pesantren mengetahui secara lebih luas mengenai berbagai permasalahan perpustakaan yang mereka hadapi, potensi, dan peluang peluang yang dapat mereka raih. Setelah masyarakat pesantren memahami persoalan perpustakaan yang mereka hadapi, maka akan dilakukan program perintisan yang meliputi pendampingan manajemen pengelolaan perpustakaan, pendampingan pelayanan perpustakaan, pengadaan koleksi bahan pustaka, katalogisasi bahan pustaka. Secara sistematatis, aspek-aspek pemberdayaan dan pendampingan yang akan dikembangkan meliputi perencanaan, pelaksanaan, serta evaluasi (Tabel 1).

Tabel. 1. Metode Pelaksanaa

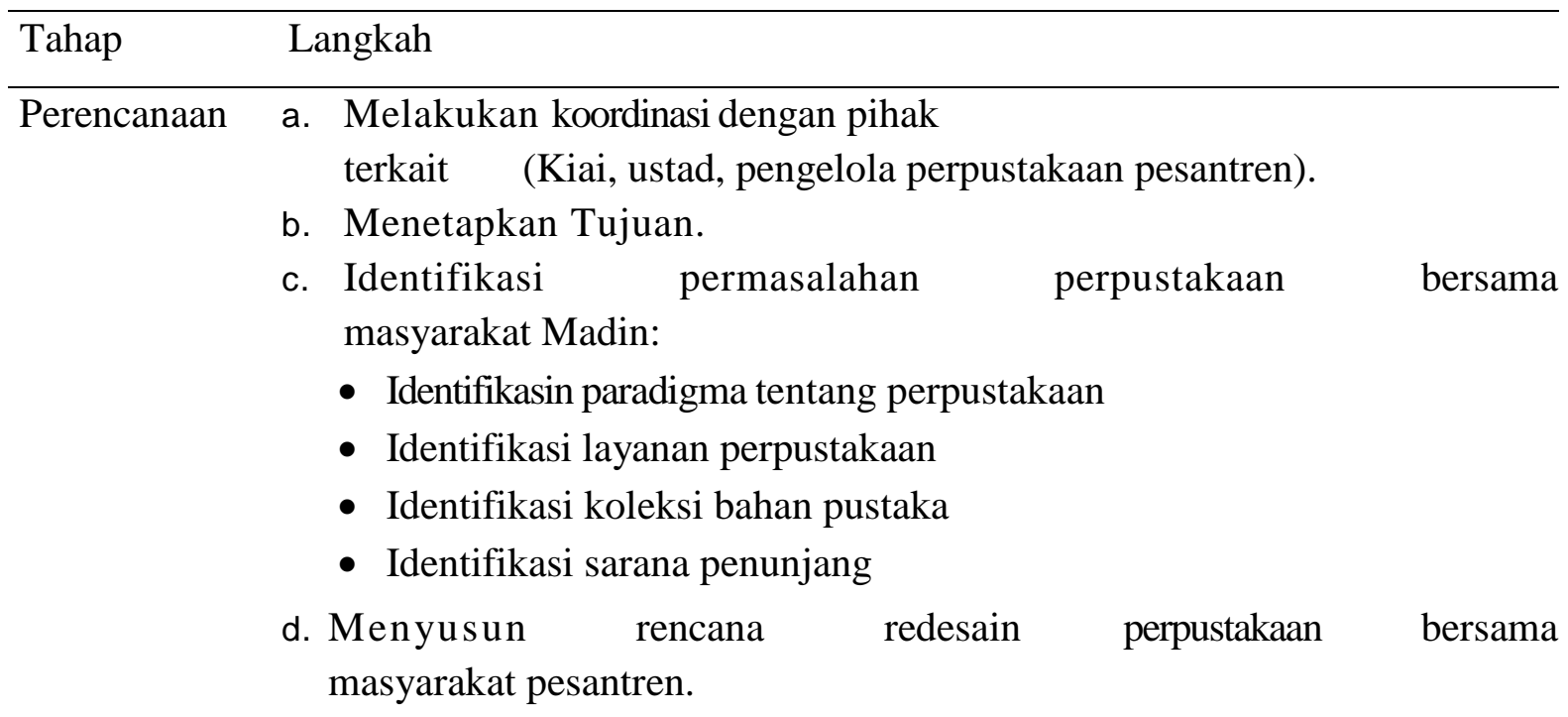




\begin{tabular}{lll}
\hline Tahap & Langkah \\
\hline Pelaksanaan & a. Training pengelolaan perpustakaan. \\
& b. Pendampinga pelayanaan perpustakaan. \\
& c. Pengadaan almari buku \\
& d. Pegadaan karpet untuk lantai \\
& e. Pengadaan koleksi baru \\
& f. Pengadaan gambar untuk dinding & \\
& g. Monitoring perkembangan kegiatan pelayanan
\end{tabular}

Evaluasi Pelayanan perpustakaan, bahan pustaka, dan sarana penunjang perpustakaan

\section{HASIL}

Pengabdian ini memberikan hasil sebagai berikut:

1. Revitalisasi kondisi fisik perpustakaan di Madin Salawiyah dengan meletakkan rak-rak buku di mushala;

2. Ustadz dan tenaga adminstrasi sekolah memiliki pengetahuan mengenai pengkatalogan buku secara sederhana dan kepustakaan;

3. Siswa Madin Salawiyah memahami pentingnya membaca dan manfaat berkunjung ke perpustakaan

\section{PEMBAHASAN}

Madrasah Diniyah Salawiyah Desa Ngombak Kecamatan Kedungjati Grobogan berdiri pada tahun 1983 dengan KH Damanhuri sebagai tokoh utama pendiri Madin ini. Pada saat ini Madin tersebut dikelola oleh Kiai Haji Mustamaji. Banyaknya ustad yang pada saat ini ada 8 orang, terdiri 5 laki-laki dan 3 perempuan, sedangkan santri saat sebanyak 72 orang. Pelaksanaan pembelajaran dilakukan sore hari, hal ini dimaksudkan anak-anak disekitar Madin mempunyai kegiatan yang positip

Madrasah Diniyah Salawiyah Desa Ngombak Kecamatan Kedungjati Grobogan Jawa Tengah. Madin ini memiliki luas 8000 meter persegi dan ditempati bangunan satu lantai ada 5 ruang dan yang dua lantai ada 10 ruang. Pada awalnya, ruang perpustakaan menjadi satu dengan ruang Ustad dan pada saat ini mulai dirintis perpustakaan dengan ruang tersendiri dengan sarana yang sangat sederhana. Namun para santri mulai antusias untuk mengunjungi perpustakaan yang baru. Hal inilah yang menjadikan motivasi bagi pengelola perpustakaan, Kiai, maupun Ustad untuk berusaha membenahinya. 


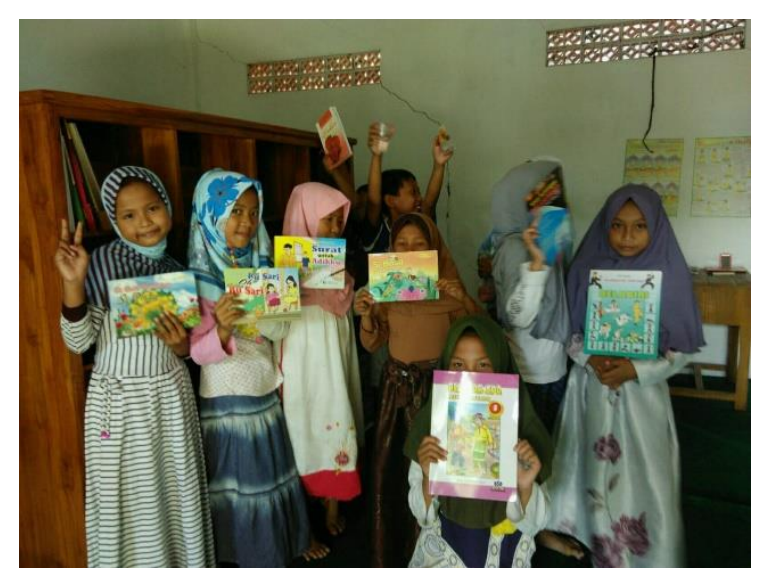

Gambar 1. Santri Madin Salawiyah

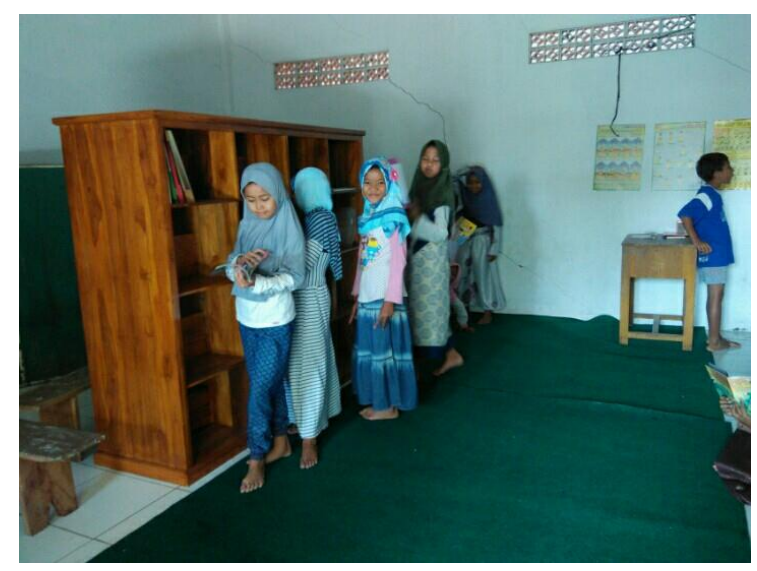

Gambar 2. Perpustakaan setelah Revitalisasi

\section{Identifikasi permasalahan Madin} Salawiyah

Ada beberapa permasalahan atau kendala yang ada di perpustakaan yang harus dicari solusinya. Selama ini yang dipahami mengenai perpustakaan adalah sebagai "gudang buku" yaitu tempat untuk menyimpan dan menumpuk buku-buku. Sehingga perpustakaan kurang nyaman untuk dijadikan sebagai tempat membaca dan mencari buku.

Belum tersedianya tempat untuk membaca (meja dan kursi) sehingga para pengunjung perpustakaan harus duduk di lantai. Layanan pustakanya masih bersifat sangat sederhana. Hal ini tentunya dapat menghambat dalam pencarian bahan pustaka karena membutuhkan waktu yang lebih lama. Disamping itu banyak bukubuku yang hilang karena tidak dikembalikan oleh peminjam sehingga mengurangi jumlah koleksi. Pelayanan yang masih manual yaitu para pengguna memilih langsung buku yang diinginkan dan mengembalikannya sendiri di rak buku menyebabkan buku tidak terklasifikasi dengan baik. Akibatnya akan menambah kerumitan dalam penelusuran pustaka.

Jumlah koleksi yang dimiliki oleh perpustakaan Madin Salawiyah kurang lebih 200 buku agama dan 450 buku umum. Koleksi buku yang dimiliki berasal dari perintisan Tim Pengabdian UPGRIS dan ada juga sumbangan dari pihak. Dengan jumlah buku yang relatif masih sedikit, tentunya dapat menggangu bagi pengguna perpustakaan. Sedangkan pengelola yang ada di perpustakaan Madin Salawiyah pada saat masih dirangkap ustad dengan jadwal bergiliran. Hal ini menjadi hambatan bagi terlaksananya tugas pustakawan karena keterbatasan pengetahuan tentang pengelolaan perpustakaan yang baik. Pustakawan memiliki peran dan fungsi penting dalam berjalannya perpustakaan 
sehingga jika tidak memiliki ijazah pustakawan, sangat dianjurkan mengikuti pelatihan kepustakaan (Yusup dan Rusmana, 2013).

Berbagai kekurangan yang ada di perpustakaan Madin Salawiyah tersebut, tentunya membutuhkan suatu solusi tepat sehingga fungsi perpustakaan dapat berjalan dengan optimal. Untuk itu perintisan pada saat ini perlu di desain perpustakaan yang mengedepankan kenyamanan dalam pelayanan. Hal ini dilakukan bersama dengan warga Madin utamanya para pengurus perpustakaan dan juga masyarakat di sekitar Madin tersebut. Sehinga pada suatu saat perpustaaan Madin Salawiyah bisa menjadi perpustakaan yang buku relatif lengkap, tempatnya nyaman, buku lebih bervariasi dan banyak serta dikelola secara profesional.

\section{a. Training pengelolaan} perpustakaan: tim pengabdi memberikan pengetahuan singkat dan sederhana disertai dengan praktik pengelolaan perpustakaan kepada ustadz dan tenaga administrasi Madin. Luaran yang dicapai adalah $70 \%$ peserta memahami materi dan merasa pentingnya pengelolaan perpustakaan yang baik untuk menjamin mutu perpustakaan. b. Pendampingan pelayanaan perpustakaan: Ustadz dan tenaga administrasi melakukan praktik pelayanan perpustakaan mulai dari pencarian buku, peminjaman buku, pengembalian buku, dan pendampingan kepada santri yang ingin meminjam buku.

c. Pengadaan almari buku: almari/rak buku ditambah 2 unit sehingga buku-buku dapat ditata secara tegak bukan ditumpuk.

d. Pegadaan karpet untuk lantai. Pengadaan ini memiliki tujuan agar santri merasa nyaman berada di perpustakaan. Luaran dari kegiatan pengadaan adalah semakin banyak santri yang berkunjung ke perpustakaan.

e. Pengadaan koleksi baru. Dengan adanya penambahan koleksi buku baru yang sesuai dengan kebutuhan santri, maka santri merasa senang dan perlu untuk membaca dan mencari informasi dari buku-buku baru yang diadakan.

f. Pengadaan gambar untuk dinding: gambar-gambar dinding terutama dengan tema keagamaan menjadi pendukung fungsi perpustakaan dalam meningkatkan pemahaman pemustaka dalam ilmu tertentu. Gambar-gambar yang diadakan 
adalah gambar tutorial wudhu, shalat, dan doa-doa harian.

g. Monitoring yang dilakukan hingga satu bulan setelah kegiatan utama berakhir menunjukkan perkembangan kegiatan pelayanan perpustakaan terlihat dari kondisi buku yang masih prima, catatan pengunjung yang semakin banyak, catatan peminjam yang semakin banyak dan ketepatan waktu pengembalian buku.

\section{KESIMPULAN}

Kesimpulan

dari perintisan perpustakaan madin salawiyah yang telah dilakukan oleh tim pengabdi dari upgris adalah: pelayanan perpustakaan dapat dioptimalisasikan untuk layanan kepada santri, kiyai, ustad dengan cara menerapkan kesederhanaan layanan, tanggung jawab, dan kemudahan. Selain itu juga dengan pelayanan perpustakaan yang baik, dapat menimbulkan dampak yang baik terhadap pengguna perpustakaan, seperti dapat memotivasi teman supaya giat membaca buku, meningkatkan pengetahuan materi pelajaran, memudahkan menyelesaikan tugas dari kiyai dan ustad

\section{SARAN}

Perlu adanya pendampingan lanjutan mengenai pengelolaan perpustakaan menggunakan catatan excel sehingga meminimalisir kehilangan buku. Perlu juga ke depan diukur pengaruh perpustakaan terhadap pemahaman santri terhadap ilmu/mata pelajaran yang diberikan di Madin Salawiyah

\section{DAFTAR PUSTAKA}

Andi Sutopo. 2012. Manajemen Perpustakaan Sekolah Profesional. Jogjakarta: Diva Press

Heriyanto, H., Yusup, P. M., \& Rusmana, A. (2013). Makna dan penghayatan profesi pustakawan. Jurnal Kajian Informasi \& Perpustakaan, 1(2), 147-156. .

Rasyid, S. A. (2005). Perpustakaan dalam Penumbuhan Sikap Gemar Membaca Siswa Madrasah. Buletin AlTuras, 11(3), 258-269.

Sulistyo Basuki. 1994. Periodisasi Perpustakaan Indonesia. Bandung: PT Remaja Rosdakarya.

Sutarno NS. 2008. Membina Perpustakaan

Desa. CV. Jakarta: Sagung Seto.

Undang-Undang Republik Indonesia Nomor 14 Tahun 2005 tentang Guru dan Dosen. Undang-Undang Republik Indonesia Nomor 20 Tahun 2003 tentang Sistem Pendidikan Nasional. 